\title{
A systematic study of the brain base arteries in the turkey (Meleagris gallopavo) ${ }^{1}$
}

\author{
Amarílis Díaz de Carvalho ${ }^{2 *}$ and Rui Campos ${ }^{3}$
}

\begin{abstract}
Carvalho A.D. \& Campos R. 2011. A systematic study of the brain base arteries in the turkey (Meleagris gallopavo). Pesquisa Veterinária Brasileira 31(Supl.1):3946. Setor de Anatomia Animal, Faculdade de Medicina Veterinária, Universidade Federal do Rio Grande do Sul, Av. Bento Gonçalves 9090, Porto Alegre, RS 91540-000, Brazil. E-mail: amarilis@bnet.com.br

Thirty heads with neck segments of turkeys (Meleagris gallopavo) were dissected for a systematic study of the arteries. The frequency of the arteries found was: Cerebral carotid artery, intercarotid anastomosis and internal ophthalmic artery (100\%). Caudal branch of the cerebral carotid artery to the right (R) vestigial artery (70\%) and developed (30\%) and to the left (L) developed (70\%) and vestigial artery (30\%). Ventral tectal mesencephalic artery in $(70 \%)$ to $\mathrm{R}$ and $(30 \%)$ to $\mathrm{L}$ was the direct branch of the cerebral carotid artery to $\mathrm{L}(70 \%)$ and to R (30\%) collateral branch of the developed caudal branch. Basilar artery to $\mathrm{L}$ in $(70 \%)$ and to $\mathrm{R}(30 \%)$ formed from the developed caudal branch; rostral ventral cerebellar artery present (86.7\%) and absent (13.3\%) to R and L. Caudal ventral cerebellar artery to R single $(73.3 \%)$, double $(23.3 \%)$ and triple $(3.3 \%)$; caudal ventral cerebellar artery to L single (73.3\%) and double (26.7\%). Dorsal spinal artery branch of caudal ventral cerebellar artery to $\mathrm{R}(80 \%)$ and to $\mathrm{L}(73.3 \%)$. The rostral branch of cerebral carotid artery showed as collateral branches the single caudal cerebral artery to R $(100 \%)$ and to $\mathrm{L}(96.7 \%)$ while in $(3.3 \%)$ it was double. The middle cerebral artery was single to $\mathrm{R}$ and L (100\%). Cerebroethmoidal artery to R and L (100\%) with its collateral branch to single rostral cerebral artery $(90 \%)$ to $\mathrm{R}$ and $(86.7 \%)$ to $\mathrm{L}$ and double $(10 \%)$ to $\mathrm{R}$ and $(13.3 \%)$ to L. Ethmoidal artery to R and to L (100\%) single. The cerebral arterial circle was rostrally and caudally opened, so that the cerebral blood supply was exclusively made by the carotid system.
\end{abstract}

INDEX TERMS: Brain vascularization, turkey, arteries.

RESUMO.- [Sistematização das artérias na base do encéfalo e suas fontes de suprimento sanguíneo em peru (Meleagris gallopavo).] Trinta cabeças de peru (Meleagris gallopavo), com segmento de pescoço, foram dissecados para o estudo sistemático das artérias. As maiores ocorrências das artérias foram: Artéria (A.) carótida do cérebro, anastomose intercarótica e A. oftálmica interna (100\%).

\footnotetext{
${ }^{1}$ Received on June 21, 2011.

Accepted for publication on November 14, 2011.

${ }^{2}$ Programa de Pós-Graduação em Ciências Veterinárias (PPGCV), Faculdade de Veterinária, Universidade Federal do Rio Grande do Sul (UFRGS), Av. Bento Gonçalves 9090, Bairro Agronomia, Porto Alegre, RS 91540-000, Brazil. *Corresponding author: amarilis@bnet.com.br

${ }^{3}$ Laboratório de Anatomia Animal, Departamento de Ciências Morfológicas, Instituto de Ciências Básicas da Saúde (ICBS), UFRGS, Av. Bento Gonçalves 9090, Porto Alegre, RS 91540-000. E-mail: rcampos@ufrgs.br
}

Ramo caudal da carótida do cérebro à direita (D) vestigial $(70 \%)$ e desenvolvido (30\%) e à esquerda (E) desenvolvido $(70 \%)$ e vestigial (30\%). A A. tectal mesencefálica ventral em $(70 \%)$ à $\mathrm{D}$ e $(30 \%)$ à $\mathrm{E}$ foi ramo direto da $\mathrm{A}$. carótida do cérebro à $\mathrm{E}(70 \%)$ e à $\mathrm{D}(30 \%)$ ramo colateral do ramo caudal desenvolvido. A A. basilar à E em (70\%) e à D (30\%) formou-se do ramo caudal desenvolvido. A. cerebelar ventral rostral presente $(86,7 \%)$ e ausente $(13,3 \%)$ à D e E. A. cerebelar ventral caudal à D única $(73,3 \%)$, dupla $(23,3 \%)$ e tripla $(3,3 \%)$. A. cerebelar ventral caudal à E única $(73,3 \%)$ e dupla (26,7\%). A. espinhal dorsal ramo da A. cerebelar ventral caudal à $\mathrm{D}(80 \%)$ e à $\mathrm{E}(73,3 \%)$. 0 ramo rostral da A. carótida do cérebro apresentou como ramos colaterais a A. cerebral caudal à D única (100\%) e à $E(96,7 \%)$ já em $(3,3 \%)$ era dupla; A. cerebral média única à $\mathrm{D}$ e $\mathrm{E}(100 \%)$. A. cerebroetmoidal à D e E (100\%) com seu ramo colateral 
a A. cerebral rostral única $(90 \%)$ à $\mathrm{D}$ e $(86,7 \%)$ à $\mathrm{E}$ e dupla $(10 \%)$ à $D$ e $(13,3 \%)$ à E. A. etmoidal à $D$ e à $E(100 \%)$ única. Observou-se que o círculo arterial cerebral foi aberto rostralmente e caudalmente e o suprimento de sangue para o encéfalo foi exclusivamente pelo sistema carotídeo.

TERMOS DE INDEXAÇÃO: Vascularização cerebral, peru, artérias.

\section{INTRODUCTION}

The increase in knowledge about the needs of blood supply to the nervous tissue of the brain has motivated a number of morphological investigation regarding the brain base arteries, and concurrently, there is growing interest in the study of this topic in different animal species.

In addition, there were some articles on the brain vascularization of birds, such as: Crowe \& Crowe (1979) in $\mathrm{Nu}$ mida meleagris (Helmeted guinea fowl), Midtgard (1984) in Larus argentatus (Seagull), Campos (1987) in Gallus gallus (Chicken) and Holliday et al. (2006) in Phoenicopterus ruber (Flamingo).

No quotation was found on the brain arterial vascularization in Meleagris gallopavo.

This study aims to systematize the brain base arteries of the turkey (Meleagris gallopavo), describing a standard model of irrigation and the main variations, in this species. This information contributes to studies in the area of comparative anatomy about the phylogenetic development of blood supply to the central nervous system.

\section{MATERIALS AND METHODS}

Thirty brains together with the spinal cord segment of turkey (Meleagris gallopavo), young and adults, 12 males and 18 females, were used in this study. The animals were proceeded from Doux Frangosul, located in Caxias do Sul, Rio Grande do Sul, Brazil and were considered unhealthy for having poor conformation and/or bone or joint development.

The animals were contained and euthanized with the combination of mebezonium iodide, embutramide and tetracaine hydrochloride $(0.2 \mathrm{ml} /$ animal), by an intravenous injection administered in the basilic vein of the arm. After, the skin was removed, the thoraco-abdominal cavity opened and the sternum was removed. The common carotid arteries were cannulated through the brachiocephalic trunk and the cranial vena cava was sectioned close to the heart. The arterial system was rinsed in chilled saline solution with 5000 IU heparin (120ml/animal), filled with a latex infection and coloured with a specific red pigment $(20 \mathrm{ml} /$ animal). The animals were immersed for an hour in running water for latex polymerization, and then the neck was sectioned near its insertion into the trunk. Afterwards a window was made in the cranial vault. The samples were fixed by submersion in $20 \%$ formaldehyde for seven days and, after that period, the brain was removed from the cranium with a segment of the cervical spinal cord. After, the dura mater was removed and the arteries were dissected for observation.

The brains with their vessels were analyzed using magnifying glass ${ }^{4}$. To record the results schematic drawings of all arteries from the brains in ventral view were made. The Nomina Anato-

\footnotetext{
${ }^{4}$ Magnifying glass with lamp LTS, 5x enlargement; Stemi SV 8, Zeiss, Goettingen, Germany.
}

mica Avium (1993) was used to describe the vessels studied. In order to illustrate the documentation, some samples were photographed. The occurrence of the vessels was expressed as the percentage of a total number of 30 brain samples examined.

\section{RESULTS}

In $100 \%$ of the samples the aortic arch emitted the left and right brachiocephalic trunk as collateral branches. The brachiocephalic trunks projected a subclavian artery for each thoracic limb (wing) and continued cranium-medially towards the neck as a common carotid artery. After a short length, it emitted the vertebralvagus trunk and continued as an internal carotid artery. The left and right internal carotid arteries, course closer to the ventral median line of the neck, penetrating through the cervical carotid canal until they reached the proximity of the cranium base, where they left the canal, diverged latero-cranially, gave off an external carotid artery to the face and continued as a cerebral carotid artery. The cerebral carotid artery reached the cranium base, penetrated through the carotid canal, projected rostro-medially and emerged within the sella turcica, caudally. Next, both cerebral carotid arteries converged rostro-medially, in $100 \%$ of the cases, to form an intercarotid anastomosis of considerable caliber located ventro-caudal to the hypophysis (Fig.1B). The cerebral carotid artery diverged rostro-dorso-laterally around the hypophysis to reach the tuber cinereum and in this trajectory gave off, as collateral branches, the intercarotid anastomosis and the internal ophthalmic artery (Fig.1B).

The cerebral carotid arteries interconnected to form the intercarotid anastomosis, as a short vessel, of considerable caliber. This anastomosis was presented in three ways: firstly in an obliquous form, secondly in an ' $\mathrm{X}$ ' aspect and thirdly in a transversal way (Table 1). The cerebral carotid artery, soon after the intercarotid anastomosis, gave off a fine-caliber collateral branch, the internal ophthalmic artery, which was rostrally projected. The internal ophthalmic artery reached the optic nerve, left the cranial cavity towards the orbital cavity through the optic foramen. In $80 \%$ of the samples, in both antimeres, the internal ophthalmic artery was present as a fine-caliber vessel, while in $20 \%$ it was presented as a medium caliber vessel. The cerebral carotid artery at the level of the tuber cinereum, divided into two terminal branches, the caudal and the rostral branch (Fig.1A, Fig.2). The caudal branch was presented differently on each antimere, while in one antimere the caudal branch was well-developed, on the opposite antimere it became the ventral tectal mesencephalic artery and its vestigial continuation immerged into the interpeduncular fossa. The caudal branch of the cerebral carotid artery was vestigial in $70 \%$ of the samples to the right and in $30 \%$ to the left, as a collateral branch of the ventral tectal mesencephalic artery. The caudal branch of the cerebral carotid artery was developed in $30 \%$ to the right and in $70 \%$ to the left, forming the basilar artery (Fig.1A, Fig.2). The ventral tectal mesencephalic artery appeared as a collateral branch of the developed caudal branch of the cerebral carotid artery. In the opposite antimere, the caudal branch became a vestigial collateral branch, of fine-caliber, of the ventral 


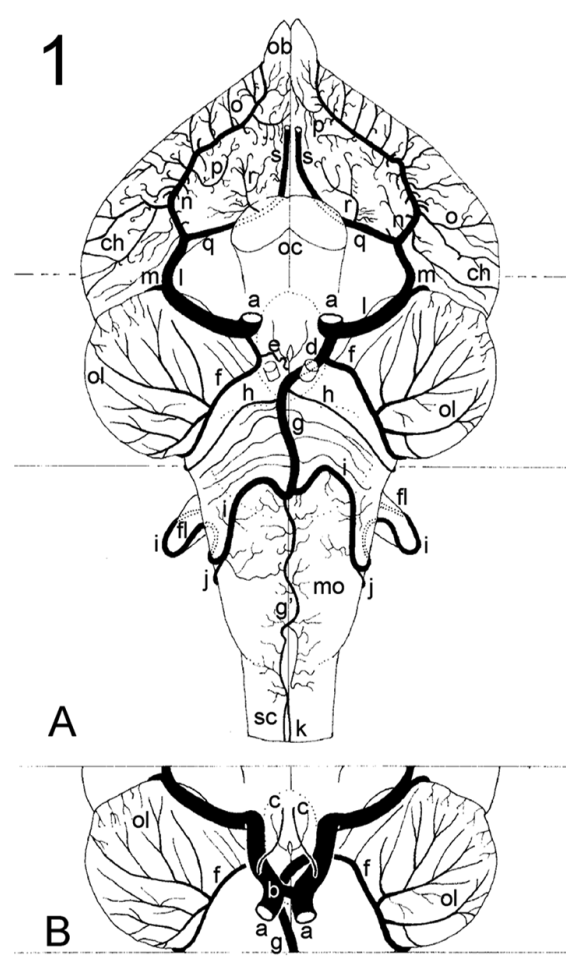

Fig.1. Schematic drawing of ventral view of the Turkey brain (Obs.20). (A) Without hypophysis. (B) Detail with intercarotid anastomosis: (a) cerebral carotid artery; (b) intercarotid anastomosis; (c) internal ophthalmic artery; (d) developed caudal branch of a; (e) vestigial caudal branch of e; (f) ventral tectal mesencephalic artery; (g) large-caliber portion of the basilar artery; (g') fine-caliber portion of the basilar artery; (h) rostral ventral cerebellar artery; (i) caudal ventral cerebellar artery; (j) dorsal spinal artery; (k) ventral spinal artery; (l) rostral branch of a; (m) caudal cerebral artery; (n) middle cerebral artery; (o) lateral hemispheric branches; (p) ventral branches; (q) cerebroethmoidal artery; (r) rostral cerebral artery; (s) ethmoidal artery; (ob) olfactory bulb; (ch) cerebral hemisphere; (oc) optic chiasm; (ol) optic lobe; (fl) flocculus; (mo) medulla oblongata; (sc) spinal cord.

tectal mesencephalic artery, which originated directly from the cerebral carotid artery. This was a medium caliber vessel, which projected inside the groove that separeted the optic lobe from the hindbrain. The ventral tectal mesencephalic artery emited several arborescent branches which vascularize all the ventral surface of the optic lobe. In $70 \%$ of the cases to the right and in $30 \%$ of the cases to the left, the ventral tectal mesencephalic artery was a direct branch of the cerebral carotid artery and projected the caudal vestigial branch (Fig.1A, Fig.2). In $30 \%$ of the cases to the right and $70 \%$ of the cases to the left, the ventral tectal mesencephalic artery was a collateral branch of the developed caudal branch of the cerebral carotid artery. The ventral tectal mesencephalic artery vascularized the ventral surface of the optic lobe and cooperated with the irrigation of the cerebellum through an anastomosis with the caudal ventral cerebellar artery in a different way (Table 2). The basilar artery was a large-caliber vessel which formed from the beginning of the ventral tectal mesencephalic artery, the developed caudal branch of the cerebral carotid artery (Fig.1A,

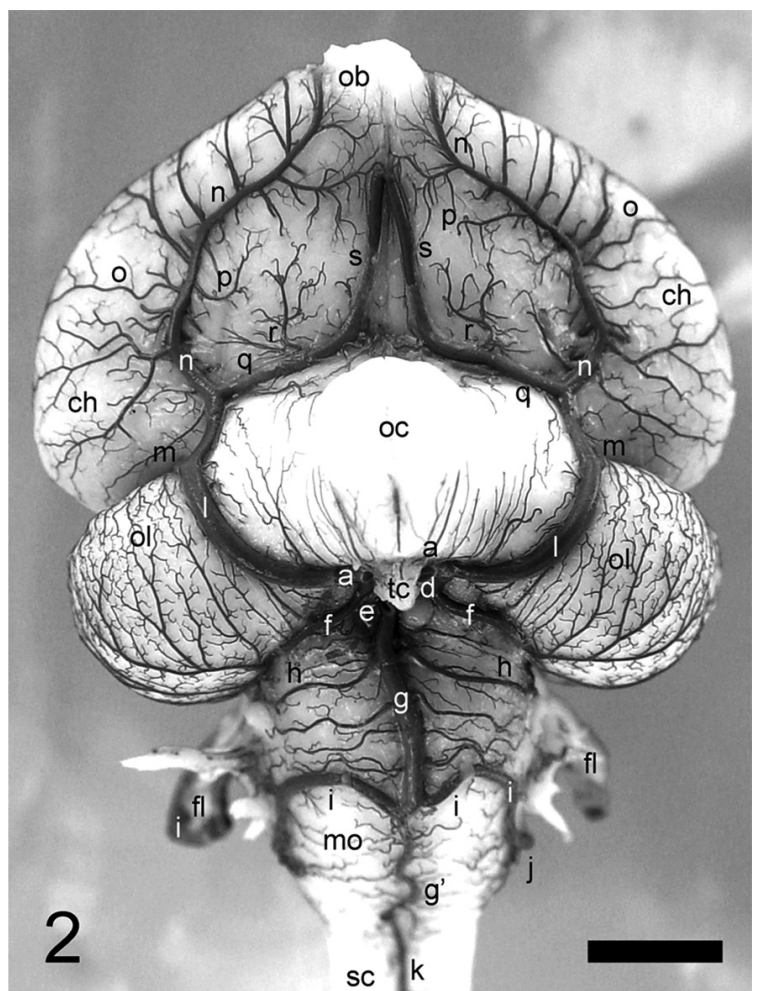

Fig.2. Picture in ventral view of turkey brain (Obs.20), without hypophysis, highlighting the major appearances of the base vessel, standard model: (a) cerebral carotid artery; (d) developed caudal branch of a; (e) vestigial caudal branch of a; (f) ventral tectal mesencephalic artery; (g) large-caliber portion of the basilar artery; (g') fine-caliber portion of the basilar artery; (h) rostral ventral cerebellar artery; (I) caudal ventral cerebellar artery; (j) dorsal spinal artery; (k) ventral spinal artery; (l) rostral branch of a; (m) caudal cerebral artery; (n) middle cerebral artery; (o) lateral hemispheric branches; (p) ventral branches; (q) cerebroethmoidal artery; (r) rostral cerebral artery; (s) ethmoidal artery. (ob) olfactory bulb; (ch) cerebral hemisphere; (oc) optic chiasm; (ol) optic lobe; (tc) tuber cinereum; (fl) flocculus; (mo) medulla oblongata; (sc) spinal cord. Bar $=4.5 \mathrm{~mm}$.

\section{Table 1. Presentations of intercarotid anastomosis}

\begin{tabular}{lccc}
\hline & $\begin{array}{c}\text { With flow to } \\
\text { right }\end{array}$ & $\begin{array}{c}\text { With flow } \\
\text { to left }\end{array}$ & - \\
\hline Oblique (\%) & 13.3 & 50 & - \\
Contact (X) (\%) & - & - & 26.7 \\
Transverse (\%) & - & - & 10
\end{tabular}

Fig.2). This vessel projected medially passing between the origins of the oculomotor nerves (III), following caudally in the median line, in a convoluted way, divided into its two main collateral branches, the left and right caudal ventral cerebellar arteries. From there it continued as a fine-caliber vessel, following the ventral median fissure, and left the cranial cavity through the foramen magnum, as a ventral spinal artery (Fig.1A, Fig.2). In its initial course, gave off to each antimere, a fine-caliber rostral ventral cerebellar artery. In $70 \%$ of the samples, the basilar artery was formed from the developed caudal branch of the left cerebral caro- 
Table 2. Cooperation of the ventral tectal mesencephalic artery in cerebellum vascularization

\begin{tabular}{lcc}
\hline & Left & Right \\
\hline Small and restricted to rostral lobe of the cerebellum (\%) & 70 & 63.3 \\
Territorial advance from 1/3 à 2/3 (\%) & 23.3 & 36.7 \\
All surface of vermis cerebellar plus flocculus (\%) & 6.7 & -
\end{tabular}

tid, in 30\% from the right cerebral carotid (Fig.1A, Fig.2). In its large-caliber portion, the basilar artery was presented in a sinuous course in $63.3 \%$ of the brains and straight in $36.7 \%$. The rostral ventral cerebellar artery appeared as a fine-caliber vessel, originated as a collateral branch of the basilar artery, just after it goes beyond the origin of the oculomotor nerves. Each artery was projected latero-dorsally, around the pontine flexure and the trigeminal nerves $(\mathrm{V})$, reached the cerebellum and supplied a small ventro-rostral area at the base of the flocculus. In $86.7 \%$ of both antimeres, the rostral ventral cerebellar artery was present and single. And in one sample it appeared very developed, vascularizing the third most rostral of the cerebellar vermis.
However, in $13.3 \%$ of both antimeres, the rostral ventral cerebellar artery was absent, due to the rostral displacement in the origin of the caudal ventral cerebellar artery, which supplied the vascular territory.

The caudal ventral cerebellar artery was the main collateral branch of the basilar artery. It projected latero-caudo-dorsally with a great sinuosity and as a single large-caliber vessel (Fig.1A, Fig.2). The caudal ventral cerebellar artery emitted as collateral branch on the lateral surface of the medulla oblongata, the dorsal spinal artery, continuing until it reached the ventral base of the flocculus, circling the flocculus dorsally until its base, forming a typical loop, to be distributed through the entire extension of its lateral surface of the cerebellar vermis. The caudal ventral cerebellar artery also gave off, between the origin of the dorsal spinal artery and the beginning of the loop, an important branch for the choroid plexus of the IV ventricle. In $73.3 \%$ on the right, the caudal ventral cerebellar artery appeared single. In 18 of these cases it showed a standard distribution course. In four of these samples, there was a territorial

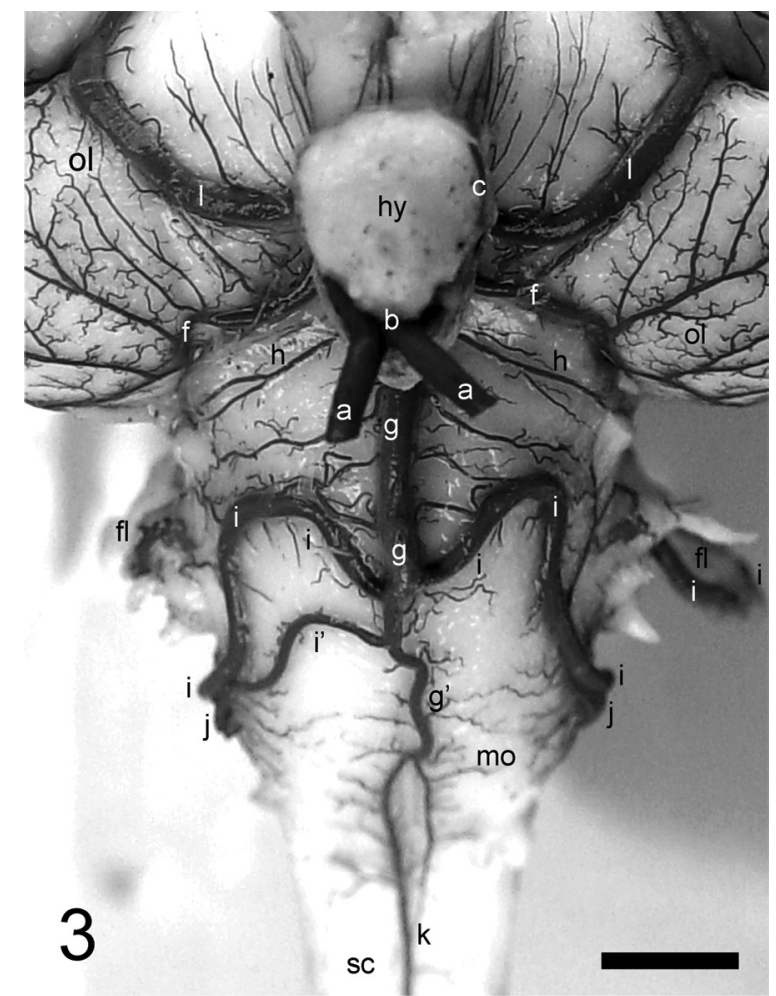

Fig.3. Picture showing detail in ventral view of turkey brain (Obs.07), highlighting the intercarotid anastomosis and the duplicity of the right caudal ventral cerebellar artery; (a) cerebral carotid artery; (b) intercarotid anastomosis; (c) internal ophthalmic artery; (f) ventral tectal mesencephalic artery; (g) large-caliber portion of basilar artery; (g') fine-caliber portion of basilar artery; (h) rostral ventral cerebellar artery; (I) caudal ventral cerebellar artery; (i') accessory caudal ventral cerebellar artery; (j) dorsal spinal artery; (k) ventral spinal artery; (l) rostral branch of a; (ol) optic lobe; (hy) hypophysis; (fl) flocculus; (mo) medulla oblongata; (sc) spinal cord. Bar $=3.5 \mathrm{~mm}$.

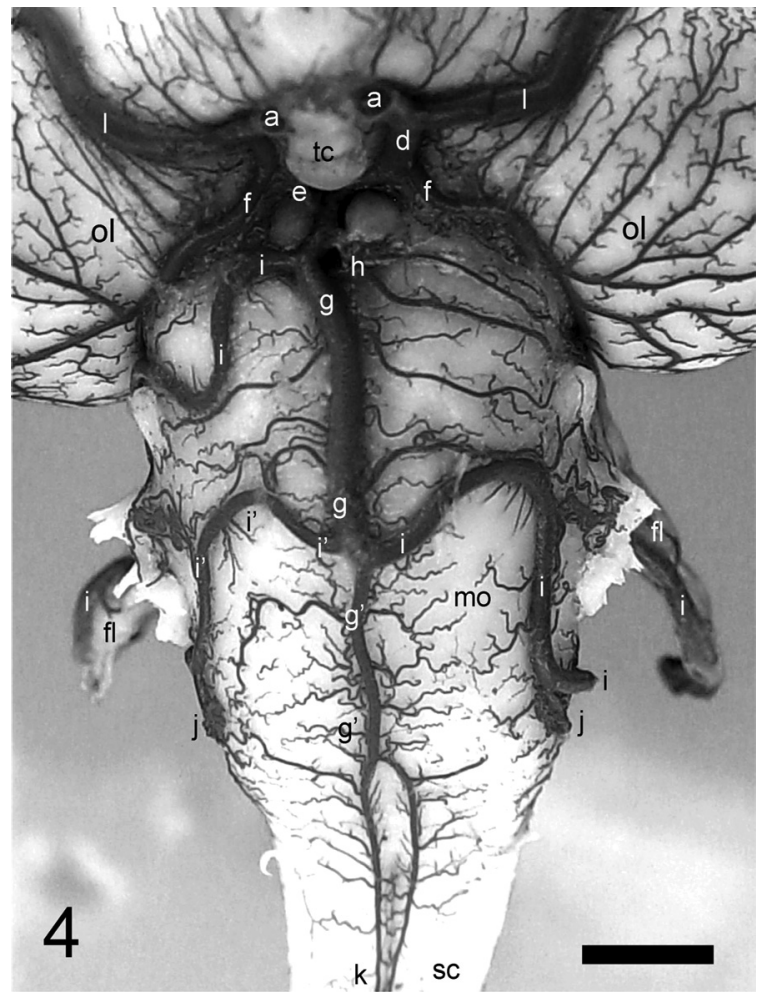

Fig.4. Picture showing detail in ventral view of turkey brain (Obs.06), to highlight the duplicity of the right caudal ventral cerebellar artery with rostral displacement of the main vessel; (a) cerebral carotid artery; (d) developed caudal branch of a; (e) vestigial caudal branch of a; (f) ventral tectal mesencephalic artery; (g) large-caliber portion of basilar artery; (g') fine-caliber portion of basilar artery; (h) rostral ventral cerebellar artery; (I) caudal ventral cerebellar artery; (I') accessory caudal ventral cerebellar artery; (j) dorsal spinal artery; (k) ventral spinal artery; (l) rostral branch of a; (ol) optic lobe; (tc) tuber cinereum; (fl) flocculus; (mo) medulla oblongata; (sc) spinal cord. Bar $=2.7 \mathrm{~mm}$. 
reduction in area. In $23.3 \%$ of the samples it was double. In four of these preparations, the caudal ventral cerebellar artery had a distribution pattern and the second component, formed the dorsal spinal artery (Fig.3). In two observations there was a rostral displacement from the origin and a normal distribution, and the second component formed the dorsal spinal artery (Fig.4). However, in another case it was observed an atrophy of the major component, forming only the ventral part of the loop and the second accessory component vascularized the choroid plexus and formed the dorsal spinal artery. In $3.3 \%$ of the samples the right caudal ventral cerebellar artery was triple (Fig.5). The first component originated more rostral and vascularized the lateral surface of the cerebellar vermis forming the loop of the flocculus. The second component, accessory I, irrigated the choroid plexus of the IV ventricle and the third vessel, accessory II, formed the dorsal spinal artery. In $73.3 \%$ to the left, the caudal ventral cerebellar artery appeared single, and in 17 of these samples it showed a standard course and distribution, on the lateral surface of the cerebellar vermis. Yet, in five of these, there was a restriction on the vascularized territory in area. In $26.7 \%$ to the left the caudal ventral cerebellar artery was double. In four of these samples the main component was standard and the accessory component formed the dorsal spinal artery. In four cases more the main component originated from the basilar artery, rostrally, and had a normal distribution after forming the loop of the flocculus. The accessory component formed the dorsal spinal artery and vascularized the choroid plexus of the IV ventricle. The dorsal spinal artery was a fine-caliber vessel originated as a collateral branch from the caudal ventral cerebellar artery, which projected caudo-dorsally, forming a vascular chain on the dorsal surface of the spinal cord, laterally, from successive anastomoses with the segmental spinal arteries. In $80 \%$ to the right and $73.3 \%$ to the left the dorsal spinal artery was presented as a standard vessel. In $13.3 \%$, in both antimeres, it was originated directly from the fine-caliber portion of the basilar artery, as a continuation of the accessory caudal ventral cerebellar artery. In $6.7 \%$ to the right, the dorsal spinal artery was emitted as a collateral branch of the accessory caudal ventral cerebellar artery. Considering that in the Obs. 25 it was a continuation of the accessory II and in Obs. 28 was a branch of the accessory artery alongside the artery for the choroid plexus of the IV ventricle. In $13.3 \%$ to the left it was emitted as a collateral branch of the accessory caudal ventral cerebellar artery, and also projected a branch for the choroid plexus of the IV ventricle. The ventral spinal artery, terminal branch of the basilar artery, was the natural continuation of the fine-caliber portion of this one, in caudal direction, running along the ventral median fissure of the spinal cord, from the foramen magnum (Fig.1A, Fig.2). In $60 \%$ of the samples, the ventral spinal artery was originated "in island" formation of the basilar artery. In $26.7 \%$ the formation "in island" was not present and in $13.3 \%$ it was double.

After the emission the caudal branch, at the level of the tuber cinereum, the rostral branch of the cerebral carotid artery was its natural continuation. The rostral branch, a large caliber vessel, was projected latero-rostrally, in arch,

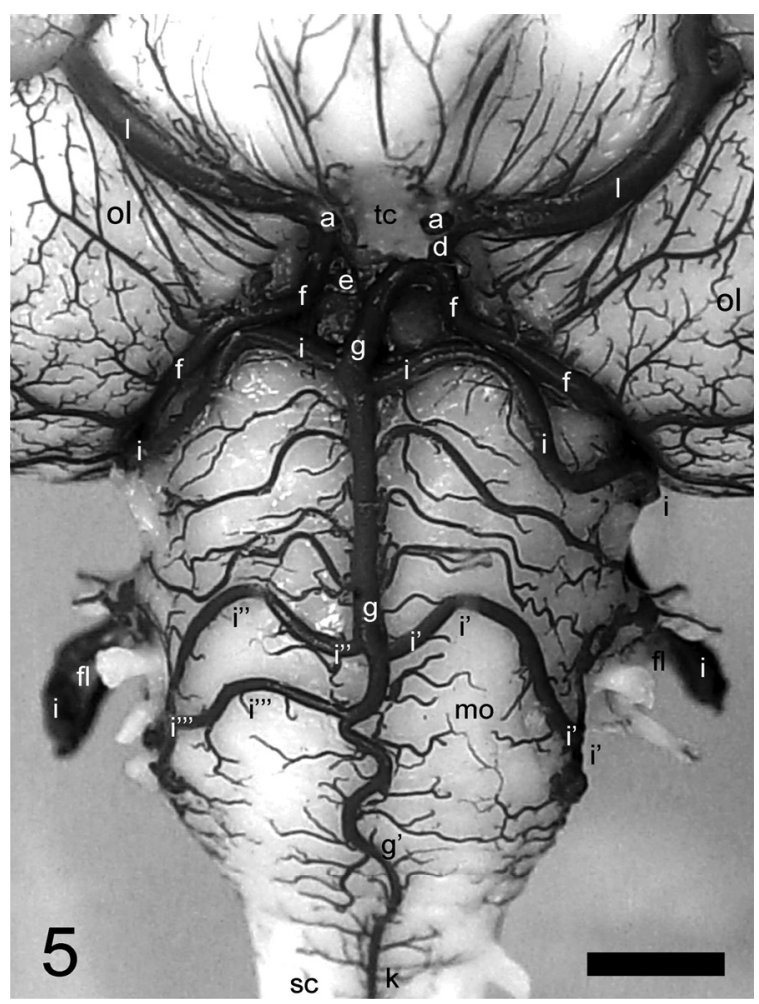

Fig.5. Picture showing detail in ventral view of turkey brain (Obs.25), to highlight the triplicity to the right and the duplicity to the left of the caudal ventral cerebellar artery: (a) cerebral carotid artery; (d) developed caudal branch of a; (e) vestigial caudal branch of a; (f) ventral tectal mesencephalic artery; (g) large-caliber portion of basilar artery; (g') fine-caliber portion of basilar artery; (i) caudal ventral cerebellar artery; (i') accessory caudal ventral cerebellar artery; (i") first accessory caudal ventral cerebellar artery; (i"') second accessory caudal ventral cerebellar artery; (l) rostral branch of a; (ol) optic lobe; (tc) tuber cinereum; (fl) flocculus; (mo) medulla oblongata; $(\mathrm{sc})$ spinal cord. Bar $=2.5 \mathrm{~mm}$.

until it reached the cerebral transverse fissure, between the optical lobe and the cerebral hemisphere (Fig.1A, Fig.2). At this point, it gave off its first collateral branch, the caudal cerebral artery. It was rostrally projected, afterwards, giving off its second collateral branch, the middle cerebral artery. Then, the rostral branch continued medially, as its terminal branch, the cerebroethmoidal artery. The caudal cerebral artery, collateral branch of the rostral branch of the cerebral carotid artery, was presented as a medium caliber vessel. Its first standard collateral branch, normal and constant, was the dorsal tectal mesencephalic artery. The occipital hemispheric branches were also emitted in both antimeres, while the dorsal cerebellar and inter hemispheric arteries were originated from the caudal cerebral artery from just one antimere. This single inter hemispheric artery ran along the cerebral transverse fissure, penetrating in the cerebral longitudinal fissure, originating dorsal hemispheric branches for both hemispheres, until the olfactory bulb. In $100 \%$ to the right and $96.7 \%$ to the left, the caudal cerebral artery was a single vessel and in 3,3\% to the left, it was double. The first component was emitted from the rostral branch in the transverse fissure of the 
brain and formed the dorsal tectal mesencephalic artery. The second component was originated right after it penetrated the cerebral transverse fissure, forming the inter-hemispheric artery. In $93.3 \%$ of the samples to the right and $80 \%$ to the left, the caudal cerebral artery was projected from the rostral branch of the cerebral carotid artery to the interior of the cerebral transverse fissure, between the optical lobe and the cerebral hemisphere. In $6.7 \%$ to the right and $20 \%$ to the left, it was emitted from the rostral branch of the cerebral carotid artery, just before the beginning of the cerebral transverse fissure. The middle cerebral artery was a single vessel, of large caliber, which formed a sinuous arch in the ventral surface of the cerebral hemisphere, from the optic tract, being projected rostro-latero-medially, until it surrounded the lateral surface of the olfactory bulb (Fig.1A, Fig.2). The middle cerebral artery emitted several lateral hemispheric branches, which ascended towards the convex surface of the cerebral hemisphere and several perforated branches to the nuclei of the striatum. In $86.7 \%$ to the right and $66.7 \%$ to the left, the middle cerebral artery formed a sinuous arch. In $13.3 \%$ to the right and $33.3 \%$ to the left, this artery formed a slightly sinuous arch. The cerebroethmoidal artery (Fig.1A, Fig.2) bent, medially, in its main axis, overpassing the optical nerve, and before it reached the median line, it was rostrally projected following the cerebral longitudinal fissure, ventrally, abandoning the cranial cavity as ethmoidal artery, along with the olfactory nerve. A small branch was projected rostrally, next to the optical nerve, forming the rostral cerebral artery. In $100 \%$, in both antimeres, the cerebroethmoidal artery was always present as a single vessel, of large caliber. The rostral cerebral artery, a collateral branch of the cerebroethmoidal artery, was a small vessel projected rostrally towards a ventral area of the cerebral hemisphere, limited by the middle cerebral and ethmoidal arteries (Fig.1A, Fig.2). In 90\% to the right and $86.7 \%$ to the left, the rostral cerebral artery was single, while in $10 \%$ to the right and $13.3 \%$ to the left, it was double. The ethmoidal artery, terminal branch of the cerebroethmoidal artery, a large-caliber vessel, followed the cerebral longitudinal fissure and abandoned the cranial cavity through the olfactory foramen, along with the homonymous nerve, distributing in the nasal cavity and nasal conchas. In $100 \%$ of the samples, in both antimeres, the ethmoidal artery was presented in a standard form.

The cerebral arterial circle of the turkey was supplied in $100 \%$ of the brains by the carotic system and it was presented opened either rostral and caudally.

\section{DISCUSSION AND CONCLUSIONS}

Regarding the aortic arch and its collateral branches, Baumel (1981), in his study about the heart and blood vessels of the birds reported that the aorta artery started in the base of the left ventricle following cranially to the right. These findings were also found in turkey. For the same author, the collateral branches of the aorta artery were the left and right brachiocephalic trunks and these were divided into the subclavian and common carotid arteries. Moreover, for Baumel (1981), the common carotid artery was divided into an internal carotid artery and a vertebralvagus trunk. The internal carotid arteries proceeded cranium-medially in the ventral median line of the neck running along the cervical carotid canal, and close to the base of the cranium each internal carotid artery projected the external carotid artery and the cerebral carotid artery. Crowe \& Crowe (1979), in Helmeted guineafowl (Numida meleagris), observed that the common carotid arteries were divided into two equal branches, the internal and external carotid arteries. For these authors, the internal carotid artery was divided into two equal vessels at the base of the cranium, an external ophthalmic artery, of larger caliber, and a cerebral carotid artery, of smaller caliber. The cerebral carotid artery proceeded rostro-medially into the carotid canal and, immediately caudal to the hypophysis, the two arteries joined by the transverse intercarotid anastomosis (Baumel 1981, Campos 1987, Campos et al. 1995). This same results were found in only $10 \%$ of the cases in turkey. As claimed by Westpfahl (1961), in Gallus, the internal carotid artery emerged from the cranial cavity, in the caudal part of the sella turcica, as a cerebral carotid artery. It was also observed that the cerebral carotid arteries, right and left, converged rostro-medially to form an intercarotid anastomosis of considerable caliber, and the same was found by Kitoh (1962), in Gallus. Richards (1967), in Gallus, mentioned that the internal carotid arteries penetrated the sella turcica and anastomosed amongst themselves in form of an "H". For Baumel \& Gerchman (1968), analyzing intercarotid anastomosis in 82 species of birds, classified the galiformes (Gallus gallus) in the " $\mathrm{H}$ " type of intercarotid anastomosis (Crowe \& Crowe 1979, Campos 1987, Campos et al. 1995). Regarding the internal ophthalmic artery, Westpfahl (1961), observed that this vessel was given off the cerebral carotid artery and abandoned the cranium with the optical nerve, anastomosing with the external ophthalmic artery (Kitoh 1962, Richards 1967, Schwarze \& Schroder 1970 Nickel 1977, Crowe \& Crowe 1979, Baumel 1981, Midtgard 1984, Campos 1987, Campos et al. 1995), and the same was found in turkey.

According to De Vriese (1905), the cerebral carotid artery divided itself beside the hypophysis into two branches, a large caliber rostral branch and a middle caliber caudal branch (Westpfahl 1961, Richards 1967, Crowe \& Crowe 1979, Midtgard 1984, Campos 1987, Campos et al. 1995), and the same was found in turkey. For Kitoh (1962), studying in Gallus, observed that the rostral and caudal branches had almost the same caliber.

In Gallus, when the caudal branch of the cerebral carotid artery is developed, it gives rise to a collateral branch, the ventral tectal mesencephalic artery, and then it continues as a basilar artery. In the opposed antimere, the caudal branch was projected from the cerebral carotid artery as ventral tectal mesencephalic artery and from this artery, a vestigial fine-caliber vessel was released medially, that dove into the interpeduncular fossa, corresponding to the continuation of the caudal branch (Baumel 1981, King \& Mclelland 1981, Campos 1987, Campos et al. 1995). While for Midtgard (1984), in gull, the ventral tectal mesencephalic artery was originated from the rostral branch of the cerebral carotid artery. According to Westpfahl (1961), 
the caudal branch formed the basilar artery in $60 \%$ to the left and $33.3 \%$ to the right, and in $6.7 \%$, there was a connection of both caudal branches to form the basilar artery, with one branch significantly finer than the other. According to Kitoh (1962), the caudal branch, to the right and left, differs considerably in caliber and the caudal branch of larger caliber originated the ventral tectal mesencephalic artery and continued as basilar artery. In the opposed antimere the caudal branch originated only the ventral tectal mesencephalic artery (Westpfahl 1961, Baumel 1981, Baumel 1993). As believed by Campos (1987), the ventral tectal mesencephalic artery was a medium-caliber vessel and was projected inside the groove that separated the optical lobe from the rhombencephalon, giving off several arborescent branches, that vascularized the whole ventral surface of the optical lobe (Kitoh 1962, Richards 1967, Campos et al. 1995), and the same was observed in turkey. One of the most important differences found in the vascularization of the brain base of the turkey, was the largest development of the ventral tectal mesencephalic artery. The ventral tectal mesencephalic artey anastomosed with the caudal ventral cerebellar artery, after the loop of the flocculus formation, cooperating with the vascularization of the cerebellum in a partial way. However, in some cases, the ventral tectal mesencephalic artery invades a lot the territory of the caudal ventral cerebellar artery. There was no remark in any reference mentioned in birds in general.

According to Campos (1987), the basilar artery ran caudally and projected as collateral branches the rostral ventral cerebellar arteries and the caudal ventral cerebellar arteries, the first of thin caliber and the second of thick caliber, in both antimeres (Westpfahl 1961, Kitoh 1962, Campos et al. 1995). Subsequently, the basilar artery was continued as a fine caliber vessel, accompanying the ventral median fissure in the medulla oblongata, until it abandoned the cranial cavity through the foramen magnum, as ventral spinal artery (De Vriese 1905, Westpfahl 1961, Kitoh 1962, Nickel 1977), as in turkey. Campos (1987) reported, in Gallus gallus, that the basilar artery was originated from the anastamosis of the right and left caudal branches of the cerebral carotid arteries, with a caliber difference between antimeres. According to Campos (1987) in Gallus, the rostral ventral cerebellar arteries, in $100 \%$ to the right and $96.6 \%$ to the left, was originated from the basilar artery, irrigating a small rostro-ventral area of the cerebellum. Still for the same author, in $3.3 \%$ of the pieces to the left, the rostral ventral cerebellar artery was not a branch of the basilar artery, but was a branch of the caudal ventral cerebellar artery in the same antimere (Campos et al. 1995). As observed by Campos (1987), the rostral ventral cerebellar artery was a small caliber vessel in the great majority of the samples, both to the right and to the left. The same was found by Richards (1967), and also in turkey. According to Campos (1987), the caudal ventral cerebellar artery was also a vessel originated from the basilar artery, present in all of the samples in both antimeres (Campos 1990). As stated by Campos (1987), there was duplicity and an accessory caudal ventral cerebellar artery was present only in the left antimere, in $3.3 \%$ of the samples. The accessory caudal ventral cerebellar artery, of fine caliber, was also a branch of the basilar artery. The main vessel presented a rostral displacement at the basilar artery's origin, as well as found in turkey. According to Richards (1967), in Gallus, the caudal ventral cerebellar artery was the main branch of the basilar artery, encircling the flocculus and dividing into small countless branches, which supplied most of the cerebellum. Campos (1987) in 3.3\% of the pieces, only to the left, the dorsal spinal artery was a direct branch of the basilar artery. In the other samples, in both antimeres, it was a collateral branch of the caudal ventral cerebellar artery (Richards 1967). The ventral spinal artery for Richards (1967) was a fine-caliber vessel originated from the caudal ventral cerebellar artery and no longer the termination of the basilar artery. However, according to the ontogenetics studies of De Vriese (1905), the basilar artery is continued as ventral spinal artery, only after it surpasses the foramen magnum. This way, the development of the caudal ventral cerebellar arteries, in the median third of the medulla oblongata, would not justify the designation adopted by this author. Regarding the results from De Vriese, the basilar artery was determined to have both large and thin caliber portions, in the turkey. For Campos (1987), the rostral branch, of large caliber, was a natural continuation of the cerebral carotid artery and bulged in arch, until it reached the cerebral transverse fissure (Kitoh 1962, Campos et al. 1995). Still for this author, the rostral branch presented as collateral branches, the caudal cerebral artery and the middle cerebral artery, and its terminal branch was the cerebroethmoidal artery (Crowe \& Crowe 1979, Baumel 1981, King \& McLelland 1981, Campos et al. 1995). According to Westpfahl (1961), the rostral branch reached the fossa sylvii and emitted the caudal cerebral artery, between the mesencephalon and the cerebral hemisphere, reaching the convex surface of the cerebral hemispheres. In mammals, the rostral branch is a collateral vessel of the caudal branch of the cerebral carotid artery. The author also reported that, after the origin of the caudal cerebral artery, the rostral branch originated the middle cerebral artery and continued as ethmoidal artery (Richards 1967, Nickel 1977). As indicated by Crowe (1979), the rostral branch emitted the ventral tectal mesencephalic artery, caudally, and afterwards it went rostrally giving off the caudal cerebral, middle cerebral, ethmoidal and rostral cerebral arteries (Midtgard 1984, Holliday 2006).

For Richards (1967), the caudal cerebral artery was given off from the rostral branch of the cerebral carotid artery, close to the transverse fissure of the brain, between the optical lobe and the cerebral hemisphere (Kitoh 1962). According to Campos (1987), the caudal cerebral artery was emitted from the rostral branch of the cerebral carotid artery at the level of the transverse fissure of the brain, in $96,7 \%$ to the right and in $100 \%$ to the left (Campos 1990 , Campos et al. 1995). Still for Campos (1987), in 3.3\% of the cases, the right caudal cerebral artery was emitted from the rostral branch before it reached the transverse fissure; these same observations were also found, in some cases, in the turkey. As reported by Campos (1987), the middle cerebral artery was the second collateral branch of the rostral bran- 
ch of the cerebral carotid artery. The middle cerebral artery was a single large caliber vessel, emitted at the level of the optic tract (Westpfahl 1961, Richards 1967, Nickel 1977, Campos 1990, Campos et al. 1995,). For those authors, in Gallus, the arch of the middle cerebral artery was not sinuous, as in turkey. This artery, according to Baumel (1981), projected several perforating branches to the ventral surface of the cerebral hemisphere and also perforating branches to the nuclei of the striated (King \& McLelland 1981, Campos 1987, Campos 1990, Campos et al. 1995). As pointed out by Campos (1987), the middle cerebral artery was projected from the rostral branch of the cerebral carotid artery. In $100 \%$ of the pieces the middle cerebral artery was a single vessel to the right and in $96.7 \%$ to the left (Campos 1990, Campos et al. 1995). For this author, in 3.3\% of the samples to the left, there was duplicity of this vessel and Campos designated the middle cerebral artery as left lateral middle cerebral artery and left medial middle cerebral artery. For King \& McLelland (1981), the terminal branch of the rostral branch of the cerebral carotid artery was the cerebroethmoidal artery that, after the optical nerve, was projected rostrally, accompanied the cerebral longitudinal fissure and abandoned the cranial cavity as ethmoidal artery (Crowe \& Crowe 1979, Baumel 1981, Midtgard 1984, Campos 1987, Campos et al. 1995). As claimed by Campos (1987), at the level of optic nerve, the cerebroethmoidal artery gave off a small collateral vessel, called rostral cerebral artery (Kitoh 1962, Richards 1967, Baumel 1968, Crowe \& Crowe 1979, Baumel 1981, Midtgard 1984, Holliday 2006), while Westpfahl (1961) did not mention the presence of the rostral cerebral artery (Schwarze \& Schroder 1970, Nickel 1977, King \& McLelland 1981). For Richards (1967), the rostral branch of the cerebral carotid artery gave off the rostral cerebral artery, a fine-caliber vessel, between the middle cerebral and ethmoidal arteries (Crowe \& Crowe 1979). However, for Campos (1987) the rostral cerebral artery, collateral branch of the cerebroethmoidal artery, presented, in the most of the samples, cases of duplicity and triplicity. For Campos (1987), the ethmoidal artery was the natural continuation of the cerebroethmoidal artery, that rostrally progressed until it abandoned the cranial cavity together with the olfactory nerve, as in turkey. For Kitoh (1962), the ethmoidal artery was the one that gave off the rostral cerebral artery and for Campos (1987), there were cases of duplicity of the ethmoidal artery in $10 \%$ of the samples to the left.

According to Baumel (1981), the cerebral arterial circle, in Gallus, was rostrally opened (Richards 1967, Campos 1987, Campos et al. 1995) as in gull (Midtgard 1984). For
Campos (1987), in Gallus, the cerebral arterial circle was always caudally closed (Kitoh 1962, Campos et al. 1995). For Westpfahl (1961), the circle was caudally opened, except in $6.7 \%$ of the pieces, in which the caudal branches were developed and closed the circle. While Midtgard (1984) in gull, reports that the circle was always caudally opened. In turkey, the cerebral arterial circle was opened rostrally and caudally.

\section{REFERENCES}

Baumel J.J. 1981 Coração e vasos sangüíneos das aves, p.1842-1869. In: Getty R. (Ed.), Sisson/Grossman's Anatomia dos Animais Domésticos. Vol. 2. $5^{\mathrm{a}}$ ed. Interamericana, Rio de Janeiro.

Baumel J.J. \& Gerchman L. 1968. The avian intercarotid anastomosis and its homologue in other vertebrates. Am. J. Anat. 122:1-18.

Baumel J.J., King A.S., Breazile J.E., Lucas A.M. \& Evans H.E. 1993. Handbook of Avian Anatomy: Nomina anatomica avium. Nuttal Ornithological Club, Cambridge.

Campos R. 1987. Contribuição ao estudo do comportamento das artérias carótidas na base do encéfalo em Gallus gallus. Dissertação de Mestrado em Anatomia Animal, Faculdade de Medicina Veterinária e Zootecnia, USP, São Paulo, SP. 141p.

Campos R. 1990. Contribuição ao estudo do comportamento e distribuição das artérias cerebral média, cerebral caudal e cerebelar ventral caudal na superfície do encéfalo em Gallus gallus. Tese de Doutorado em Anatomia Animal, Faculdade de Medicina Veterinária e Zootecnia, USP, São Paulo, SP. 155p.

Campos R., Ferreira N. \& Marrone A.C.H.1995. A sitematic study of encephalic blood supply in Gallus gallus. J. Anat. Embryol. 100:111-121.

Crowe T.M. \& Crowe A.A. 1979. Anatomy of the vascular system of the head and neck of the helmeted guinea fowl Numida meleagris. J. Zool. 188:221-233.

De Vriese B. 1905. Sur la signification morphologique des artères cérébrales. Archs Biology 21:357-457.

Holliday C.M., Ridgely R.C., Balanoff A.M. \& Witmer L.M.2006. Cephalic vascular anatomy in Flamingos (Phoenicopterus ruber) based on novel vascular injection and computed tomographic imaging analyses. Anat. Rec. A 288:1031-1041.

King A.S. \& McLelland, J. 1981. Form and Function in Birds. Academic Press, London.

Kitho J. 1962. [Comparative and topographical anatomy of the fowl. XII. Observation on the arteries with their anastomoses in and around the brain in the fowl] (in japanese). Jpn. J. Vet. Sci. 24:141-150.

Midtgard U. 1984. The blood vascular system in the head of the herring gull (Larus argentatus). J. Morphol. 179:135-152.

Nickel R., Schummer A. \& Seiferle E. 1977. Anatomy of the Domestic Birds. Verlag Paul Parey, Berlin.

Richards S.A. 1967. Anatomy of the arteries of the head in the domestic fowl. J. Zool. 152:221-234.

Schwarze E. \& Schroder E. 1970. Compêndio de anatomia veterinária: anatomia de las aves. Acribia, Zaragoza.

Westpfahl U. 1961. Das Arteriensystem des Haushuhnes (Gallus domesticus). Wissenschaftliche Zeitschrift der Humboldt 10:93-124. 